\section{B A Institute of \\ YK Business Administration \\ 六下 \\ Karachi \\ Leadership and Ideas for Tomorrow}

Business Review

Volume 2 Issue 2 July-December 2007

7-1-2007

\title{
The casual link between stock returns and trading volume: Some evidence from an emerging market
}

Abdul Rashid

Institute of Business Administration, Karachi, Pakistan

Follow this and additional works at: https://ir.iba.edu.pk/businessreview

Part of the Finance Commons, and the Finance and Financial Management Commons

(c) (;)

This work is licensed under a Creative Commons Attribution 4.0 International License.

\section{Recommended Citation}

Rashid, A. (2007). The casual link between stock returns and trading volume: Some evidence from an emerging market. Business Review, 2(2), 67-87. Retrieved from https://doi.org/10.54784/1990-6587.1390

This article is brought to you by iRepository for open access under the Creative Commons Attribution 4.0 License and is available at https://ir.iba.edu.pk/businessreview/vol2/iss2/5. For more information, please contact irepository@iba.edu.pk. 


\title{
ARTICLE
}

\section{The Causal Link between Stock Returns and Trading Volume: Some Evidence from an Emerging Market}

\author{
Abdul Rashid \\ Institute of Business Management, Karachi Pakistan
}

\begin{abstract}
\end{abstract}
This paper investigates the dynamic association between daily stock index returns and percentage trading volume changes. To proceed with this, linear and nonlinear Granger causality tests are applied to the Karachi Stock Exchange (KSE) data. The analysis covers the span of about 5 years with 1266 daily observations. The same methodology is employed for two non-overlapping sub-periods to examine the robustness of the results.

Unidirectional linear Granger causality from stock returns to trading volume is observed for the entire sample period and for both the sub-periods as well. The null hypothesis of linear Granger noncausality from percentage volume changes to stock returns is rejected only in optimal lag length for the second sub-period. Regarding nonlinear Granger causality, the modified Baek and Brock's test (1992a) for nonlinear Granger causality provides evidence of significant unidirectional nonlinear Granger causality from percentage volume changes to stock returns in both the sub-periods for all the common lag lengths used but not for vice versa. The analysis exposed that volume has significant nonlinear explanatory power for stock returns, whereas stock returns have linear explanatory power for trading volume.

JEL Classification Code: G12; C14

Keywords: Stock Prices; Trading Volume; Nonlinear Granger Causality; Karachi Stock Exchange

\section{INTRODUCTION}

ost of the empirical work on stock market has focused traditionally on whether future stock prices moments can be projected or not. Through a brief review of the literature, it is found two different groups of studies in this area. The first one considers those studies that tested the Market Efficient Hypothesis (MEH) or/and Random Walk Hypothesis (RWH) for stock markets. A large number of studies including Larson (1960), Alexander (1961, 1964), Granger and Morgenstern (1963), Mandelbort (1963) and Fama $(1963,1970)$ have claimed that stock markets are weak form efficient i.e., past price movements could not be used to predict future prices changes. In contrast, some studies have been rejected the Random Walk 
Hypothesis for stock prices (e.g., Fama (1965), Lo and Mackinlay (1988), Husain (1997), Rashid (2005, 2006)).

The second mass of studies on stock market has focused primarily on to identify the financial and socio-economic factors that have significant associations with stock prices. These studies have generally used OLS regression analysis, cointegration and causality techniques to explore the relationship between stock prices and the other variables such as profits, book-to-market value, term premium, dividend yields, exchange rates, interest rates, inflation, money supply, output growth, etc.

One common problem with this sort of studies is that stock prices are fluctuated more frequently, while the financial and economic variables are relatively less volatile. Moreover, the factors/news that causes changes in stock prices may be different from the factors that are responsible for the changes in these variables. Under this scenario, these variables may not be able to reflect the available set of relevant information on the stock market.

Trading volume, however, is another most frequent variable like stock prices and perhaps both the financial variables are affected by the same sort of risk. Stock prices and trading volume are two prime indicators of stock market performance and jointly determined by the same market fluctuations. As with stock prices, aggregate trading volume mainly reflects investors' expectations on the future performance. As mentioned earlier, most of the empirical studies in existing literature have focused on only stock prices/returns for forecasting with a very little attention on trading volume. The study by Blume et al. (1994) has highlighted that trading volume captures the important information about speculators' trading activities and hence, movements in trading volume may be useful in forecasting of stock price dynamics. Another study by Gallant et al. (1992) claimed that more can be learned about the stock market behavior through studying the jointly dynamics of stock prices and trading volume rather than by focusing only on one of them.

The empirical work on the stock price-volume relation focused on the study of causality between stock prices and trading volume ${ }^{1}$. Causality tests can provide useful information on whether knowledge of past stock prices (trading volume) movements improves short-run forecasts of current and future movements in trading volume (stock prices). The traditional Granger causality test is only useful to examine the linear relation; however, it is unable to explore the nonlinear relationship between two variables (for details, see Baek and Brock (1992a) and Hiemstra and Jones (1993)).

\footnotetext{
${ }^{1}$ See for example, among others, Rogalski (1978), Smirlock and Starks (1988), and Jain and Joh (1988).
} 
Explanations for nonlinearities between stock prices and trading volume is defined as follows. As said by Granger (1986), univariate and multivariate nonlinear models represent the proper way to model a real world that is "almost certainly nonlinear." Hsieh (1991) and Brock (1993) highlighted that the recent focus on nonlinear structure in stock price movements is motivated by the richer types of asset behavior that nonlinear models provide researchers. Large stock price swings and abrupt changes in the stock market volatility can be properly modeled with nonlinear models ${ }^{2}$.

LeBaron (1992) used regression models similar to the one used by Campbell et al. (1993) and documented evidence of significant nonlinear interactions between stock returns and trading volume in the New York Stock Exchange. It is now widely accepted that nonlinearity is present in stock price-trading volume associations. The study thus used both linear and nonlinear causality tests to investigate the dynamic interactions between stock prices and trading volume. The nonlinear Granger causality test used here is based on nonparametric estimators of temporal relations within and across time series. It is modified version of Baek and Brock's (1992a) nonlinear Granger causality test.

The core purpose of this study is to examine whether the information on trading volume can be used to predict the changes in stock prices. This analysis has very useful implications for both hedgers and speculators. Most hedgers do not employ continuous hedges. Instead, they select the times at which they want protection against adverse changes. Definitely, knowledge of stock price-trading volume association can be used for forecasting future movement of stock prices effectively.

The remainder of the article is organized as follows. Section 2 will discuss the theoretical linkages between stock prices and trading volume. This section will also discuss how volume and price move together. Section 3 will briefly review some recent empirical work in this field. Section 4 will present the notation of Granger causality and traditional linear tests in brief. This section will also discuss Baek and Brock's (1992a) nonparametric approach to nonlinear Granger causality testing and the modified version of their test, which is applied here. Estimations and interpretations of the results will follow in Section 5. Finally, Section 6 will conclude with a summary of this document.

\section{THEORETICAL DISCUSSION}

The theoretical studies that provided explanations for the presence of a causal link between stock prices and trading volume can be divided into four categories. The

${ }^{2}$ Hisieh and Patterson (1985), Scheinkman and Lebaron (1989), Brock et al. (1991), among others, provided evidence of significant nonlinear dependence in stock returns. 
studies in the first category include Copeland (1976) and Jennings et al. (1981) that developed the sequential information arrival models. According to these asymmetric models, there is a positive relationship between stock prices and trading volume and causality runs in either direction. Owing to the sequence information flow, lagged trading volume could have predictive power for current stock prices, and vice versa.

The second category includes Lakonishok and Smidt's study (1989) that explained the relation between current trading volume and past stock prices via tax- and nontax-related motives. Their analysis confirmed that the dynamic relation is negative for tax-related trading motives and this relation turns into positive for certain nontax-related trading motives.

The third group of theoretical studies consists of the mixture of distributions models of Clark (1973) and Epps and Epps (1976). These models suggest a positive relation between current stock returns variance and trading volume in different ways. For example, the mixture model of Epps and Epps (1976) used trading volume as a proxy to measure disagreement as traders revise their reservation prices based on the arrival of new information into the market. Their models thus suggested a positive causal relation running from trading volume to absolute stock returns. In contrast, the mixture model of Clark's (1973) used trading volume as a proxy for the speed of information flow and unable to find any significant causal link between trading volume and stock prices.

Noise trader models are included in fourth category. These models stated that aggregate stock returns are positively autocorrelated in the short run, but negative in the long run. A positive causal relation from trading volume to stock prices is based on the assumption made in these models that the trading volume strategies pursued by noise traders cause stock prices to move. On the other hand, a positive causal link from stock returns to volume is consistent with the positive-feedback trading strategies of noise traders, for which the decision to trade is conditioned on the past stock price movements (for details, see Delong et al. (1990)).

\section{LITERATURE REVIEW}

In 1959, Osborne, first time, hypothesized that securities prices could be as a lognormal distribution with the variance term dependent on the trading volume. He concluded that the log return process was a Brownian motion process.

Seven years later, another study by Ying (1966) applied a series of statistical tests to a six-year daily series of price and volume. Prices were adjusted by quarterly dividend and similarly trading volume was normalized by the number of shares outstanding to avoid any biases from issues from larger number of outstanding shares. Using the New York Stock Exchange (NYSE) daily percentage volume and Standard and Poor's 500 index returns data covering the period from January 1957 to 
December 1962, he found that a large increase in volume is usually accompanied by a large price change.

He also concluded that if the stock trading volume has decreased (increased) five consecutive trading days, the price will tend to fall (rise) over the next four days. These two studies illustrate the origins of the analysis of stock price-trading volume associations. However, below the study reviews and summarizes some recent studies in this field.

The study by Ganllant et al. (1992) applied nonlinear impulse response functions to examine the nonlinear associations between stock returns and trading volume on the New York Stock Exchange (NYSE). Their study provided evidence that stock returns are playing leading role. They concluded that stock returns might successfully be used to forecast the future movements in trading volume.

Hiemstra and Jones (1994) used the traditional linear Granger causality tests along with the modified version of Baek and Brock's (1992a) nonlinear Granger causality test to expose the causal relations between stock prices and trading volume. The study used daily closing prices for Dow Jones Price Index and trading volume on the New York Stock Exchange (NYSE). The sample period is 1915 to 1990. They found evidence of significant unidirectional linear Granger causality from stock returns to percentage volume changes and bidirectional nonlinear Granger causality between stock returns and percentage changes in trading volume.

Blume et al. (1994) studied the informational content of trading volume. Rather than describing the simple correlation between stock prices and trading volume, they set out to show how trading volume could affect market behavior. They found that trading volume provides information on the precision and dispersion of information signals, which stock prices alone do not. They suggested the use of trading volume as an additional statistic to observe the stock market movements.

Ghysels et al. (2000) investigated the causality between the series of returns and transaction volumes in high frequency data. Their data set consists of 20405 observations on returns and volumes of trades of the Alcatel stock, recorded on the Paris Stock Exchange. The study covers the period from July to August 1996. They found co-movements between volumes and transaction prices and proposed tests for Granger causality. Using standard Granger causality test, they reported that there is a causal relation between stock returns and volume. However, their empirical results indicate that causality directions vary in time and depend on the sampling scheme.

Chordia and Swaminathan (2000) studied the interaction between trading volume and predictability of short-term stock returns. They found that daily returns of stocks with high trading volume lead daily returns of stocks with low trading volume. They concluded that "trading volume plays a significant role in the dissemination of market wide information". 
Chen et al. (2001) used linear Granger causality test to examine the dynamic relation between returns, volume and volatility of stock indexes. The period of the study is 1973 to 2000. Using data for nine national markets viz. New York, Tokyo, London, Paris, Toronto, Milan, Zurich, Amsterdam, and Hong Kong, they found a significant positive correlation between trading volume and the absolute value of the stock prices. Regarding Granger causality, their results provide evidence that for some countries, returns cause volume and volume causes returns. As stated by them, the results are robust across the nine national markets.

Fan et al. (2003) examined the relationship between trading volume and stock returns for two Chinese A-share markets and ten individual stocks in the energy sector. Their study also investigated the effects of exogenous government policies on the relationship between trading volume and stock return. Using daily data covering the period from January 1, 1997 to December 31, 2002, they found that the relationship between trading volume and return is asymmetrically V-shaped with the response of trading volume to a rising return being stronger than that to a falling return. Based on Granger causality test, they reported a strong evidence of return causing volume; volume has only a weak effect on future returns but a strong and predictable effect on absolute returns.

\section{METHODOLOGY FRAMEWORK}

This section first presents the definition of Granger causality and then briefly outlines the basic approach to explore the linear Granger causality. Finally, this section provides a detailed discussion of the modified Baek and Brock's (1992a) test as proposed by Hiemstra and Jones (1994) for testing nonlinear Granger causal relations, which cannot be detected by the traditional linear causality tests.

The Granger (1969) definition for causality of two stationary time series $Z_{t}$ and $R_{t}$ is defined in general form as follows. Let $P_{r}\left(Z_{t} \mid I_{t-1}\right)$ be the conditional probability distribution of $Z_{t}$ given the bivariate information set $I_{t-1}$ consisting of a $k$-length lagged vector of $Z_{t}$ (say $Z_{t-k}^{k}$ ), and $n$-length lagged vector of $R_{t}$, say $R_{t-n}^{n}$. Given lags $k$ and $n$, the time series $\left\{R_{t}\right\}$ does not strictly Granger cause $\left\{Z_{t}\right\}$ if:

$$
P_{r}\left(Z_{t} \mid I_{t-1}\right)=P_{r}\left(Z_{t} \mid\left(I_{t-1}-R_{t-n}^{n}\right)\right) \quad t=1,2, \ldots,
$$

where, $\operatorname{Pr}(\bullet)$ denotes conditional probability,

$$
Z_{t-k}^{k} \equiv\left(Z_{t-1}, Z_{t-2}, \cdots, Z_{t-k}\right) \quad \mathrm{k}=1,2, \ldots, \quad \mathrm{t}=1,2, \ldots,
$$




$$
R_{t-n}^{n} \equiv\left(R_{t-1}, R_{t-2}, \ldots, R_{t-k}\right)
$$$$
\mathrm{n}=1,2, \ldots, \quad \mathrm{t}=1,2, \ldots,
$$

If the equality in equation $\{1\}$ does not hold, then information of past $R$ values helps to predict current and future $Z$ values, then $R$ said to be strictly Grangercause $Z$. Similarly, a lack of instantaneous Granger causality from $R$ to $Z$ occurs if:

$$
P_{r}\left(Z_{t} \mid I_{t-1}\right)=P_{r}\left(Z_{t} \mid\left(I_{t-1}+R_{t}\right)\right)
$$

where the bivariate information set is modified to include the current value of $Z$. If the equality in equation $\{2\}$ does not hold, $Z$ is said to instantaneously Granger cause $R$. In case of strict Granger causality (as shown in equation $\{1\}$ and $\{2\}$ ), the past value of $Z$ influencing (in Granger sense) the present and future value of $R$. Whereas, instantaneous causality relates to the present value of $Z$ influence the present $R$. However, this study considers only strict Granger causality owing to complications in distinguishing between instantaneous causality and instantaneous feedback (for more on this topic, see Granger and Newbold (1986)).

\subsection{TESTING PROCEDURE FOR LINEAR GRANGER CAUSALITY}

In bivariate case, the presence of Granger causality is tested by evaluating the predictive power of one time series for another. Because linear least squares predictors are used in implementing the test, the linear approach only tests for causality in the means between economic variables (for details, see Granger and Newbold (1986)). In this study, a well-known Granger test is used to examine the linear causality. The test involves estimating a linear reduced-form vector autoregression (VAR):

$$
\begin{aligned}
& S P_{t}=a_{0}+a_{1} S P_{t-1}+\cdots+a_{k} S P_{t-k}+b_{1} T V_{t-1}+\cdots+b_{n} T V_{t-n}+u_{t} \\
& T V_{t}=a_{0}^{\prime}+a_{1}^{\prime} T V_{t-1}+\cdots+a_{n}^{\prime} T V_{t-n}+b_{1}^{\prime} S P_{t-1}+\cdots+b_{k}^{\prime} S P_{t-k}+v_{t}
\end{aligned}
$$

where $k$ and $n$ are lag orders, and $S P_{t}$ and $T V_{t}$ are stock prices and trading volume, respectively. The regression residuals, $\left\{u_{t}\right\}$ and $\left\{v_{t}\right\}$, are assumed to be mutually independent and individually i.i.d. with zero mean and constant variance.

To test for strict Granger causality for all possible pairs of $\left\{S P_{t}, T V_{t}\right\}$ in this linear framework, a standard joint test $\left(F-\right.$ or $\chi^{2}-$ test $)$ is used to determine whether lagged value of one time series (say $S P_{t}$ ) has significant linear predictive power for current value of another series (say $T V_{t}$ ). The null hypothesis that $T V_{t}$ does not 
strictly Granger cause $S P_{t}$ is rejected if the coefficient on the lag values of $T V_{t}$ in equation $\{3\}$ are jointly significantly different from zero. i.e., $b_{1} \neq b_{2} \neq \cdots \neq b_{k} \neq 0$. Bidirectional causality (or, feedback) exists if the null hypothesis that $S P_{t}$ does not strictly Granger cause $T V_{t}$ is also rejected.

\subsection{TESTING PROCEDURE FOR NONLINEAR GRANGER CAUSALITY}

The linear approach to causality testing is unable to find nonlinear causal relations. Brock (1991) presents a simple bivariate nonlinear model to illustrate how the linear causality tests, such as the Granger test, can fail to uncover nonlinear predictive power. He uses the following model:

$$
S P_{t}=\beta T V_{t-n} \times S P_{t-K}+\eta_{t}
$$

where $T V_{t}$ and $\eta_{t}$ are mutually independent and individually i.i.d.N $(0,1)$ time series, $\beta$ denotes a parameter, and $k$ and $n$ denote lag lengths. Note that $S P_{t}$ depends on a past value of $T V_{t}$, yet linear tests would incorrectly indicate that there is no lagged dynamic relation between $S P_{t}$ and $T V_{t}$, since all autocorrelations and cross correlations are zero.

Baek and Brock (1992a) therefore proposed a nonparametric statistical method for uncovering nonlinear causal associations. They suggested the use of correlation integral, an estimator for spatial probabilities across time, to explore causal relationship between two time series. Below briefly the Baek and Brock's (1992a) procedure to testing for non-linear Granger causality is discussed.

\subsection{THE BAEK AND BROCK APPROACH TO CAUSALITY TESTING}

Let consider $S P_{t}$ and $T V_{t}$ are two time series that assumed strictly stationary and weakly dependent. Denote the m-length lead vector of $S P_{t}$ by $S P_{t}^{m}$ and the klength and n-length lag vectors of $S P_{t}$ and $T V_{t}$, respectively, by $S P_{t-k}^{k}$ and $T V_{t-n}^{n}$, that is

$$
\begin{array}{ll}
S P_{t}^{m} \equiv\left\{S P_{t}, S P_{t+1}, S P_{t+2}, \ldots, S P_{t+m-1}\right\} & \mathrm{m}=1,2, \ldots, \mathrm{t}=1,2, \ldots, \\
S P_{t-k}^{k} \equiv\left\{S P_{t-1}, S P_{t-2}, \ldots, S P_{t-k+1}, S P_{t-k}\right\} & \mathrm{k}=1,2, \ldots, \mathrm{t}=\mathrm{k}+1, \mathrm{k}+2, \ldots,
\end{array}
$$




$$
T V_{t-n}^{n} \equiv\left\{T V_{t-1}, T V_{t-2}, \ldots, T V_{t-n+1}, T V_{t-n}\right\}
$$

$n=1,2, \ldots, \quad t=n+1, n+2, \ldots$,

For given values of $\mathrm{m}, \mathrm{k}$ and $\mathrm{n} \geq 1$ and for e $>0$, stock returns $\left\{S P_{t}\right\}$ fails to nonlinearity Granger cause trading volume $\left\{T V_{t}\right\}$ if:

$$
\begin{array}{r}
\left.\operatorname{Pr}\left\|S P_{t}^{m}-S P_{s}^{m}\right\|<e_{1}\left\|S P_{t-k}^{k}-S P_{s-k}^{k}\right\|<e_{1},\left\|T V_{t-n}^{n}-T V_{t-n}^{n}\right\|<e_{2}\right\} \\
=\operatorname{Pr}\left\{\left\|S P_{t}^{m}-S P_{s}^{m}\right\|<e_{1}\left\|S P_{t-k}^{k}-S P_{s-k}^{k}\right\|<e_{1}\right\}
\end{array}
$$

where $\operatorname{Pr}\{\bullet\}$ denotes probability and $\|\cdot\|$ denotes the maximum norm ${ }^{3}$. The probability on the left-hand side of equation $\{6\}$ is the conditional probability that $\left\|S P_{t}^{m}-S P_{s}^{m}\right\|<e_{1}$, given the pair of k-histories $S P_{t}$ differ by less than $e_{1}$, i.e., $\left\|S P_{t-k}^{k}-S P_{s-k}^{k}\right\|<e_{1}$, and the pair of n-histories of $T V_{t}$ differ by less than $e_{2}$, i.e., $\left\|T V_{t-n}^{n}-T V_{s-n}^{n}\right\|<e_{2}$. The probability on the right-hand side of equation $\{6\}$ is the conditional probability that two arbitrary m-length lead vectors of $S P_{t}$ are within a distance $e_{1}$ of each other, given that their corresponding k-length lag vectors of $S P_{t}$ are at a distance smaller than $e_{1}$ of each other.

As stated by Baek and Brock (1992a), this definition depends on the number of lags of future prediction which is one for this study (then, $S P_{t}^{1}=S P_{t}$ ), the $e_{1}, e_{2}$; the number of k-length and n-length lags vectors of $S P_{t}$ and $T V_{t}$, respectively.

To test the null hypothesis $H_{0}: T V_{t}$ does not nonlinearly Granger cause $S P_{t}$, it is useful to express the conditional probabilities in terms of the corresponding ratios of joint probabilities. Let $C_{1}(m+k, n, e) / C_{2}(k, n, e) \quad$ and $C_{3}(m+k, e) / C_{4}(k, e)$ denote the ratios of joint probabilities corresponding to lift-hand side and right-hand side of equation $\{6\}$, where $e \equiv\left(e_{1}, e_{2}\right)$. These join probabilities are defined ss $^{4}$ :

\footnotetext{
${ }^{3}$ The maximum norm for $Z=\left(z_{1}, z_{2}, \ldots, z_{k}\right) \in R^{k}$ is defined as $\max (Z), i=1,2, \ldots, k$. ${ }^{4}$ By definition, the conditional probability $\operatorname{Pr}(\mathrm{A} / \mathrm{B})$ can be expressed as the ratio $\operatorname{Pr}(\mathrm{A} \cap \mathrm{B}) / \operatorname{Pr}(\mathrm{B})$.
} 


$$
\begin{gathered}
C_{1}(m+k, n ; e)=\operatorname{Pr}\left\{\left\|S P_{t-k}^{m+k}-S P_{s-k}^{m+k}\right\|<e_{1},\left\|T V_{t-n}^{n}-T V_{s-n}^{n}\right\|<e_{2}\right\} \\
C_{2}(k, n ; e)=\operatorname{Pr}\left\{\left\|S P_{t-k}^{k}-S P_{s-k}^{k}\right\|<e_{1},\left\|T V_{t-n}^{n}-T V_{s-n}^{n}\right\|<e_{2}\right\} \\
C_{3}(m+k ; e)=\operatorname{Pr}\left\{\left\|S P_{t-k}^{m+k}-S P_{s-k}^{m+k}\right\|<e_{1}\right\} \\
C_{4}(k ; e)=\operatorname{Pr}\left\{\left\|S P_{t-k}^{k}-S P_{s-k}^{k}\right\|<e_{1}\right\}
\end{gathered}
$$

For given values of $m, k$, and $n \geq 11$ and $e>0$, the null hypothesis $H_{0}$ can then be expressed as:

$$
H_{0}: \quad C_{1}(m+k, n ; e) / C_{2}(k, n ; e)-C_{3}(m+k ; e) / C_{4}(k ; e)=0
$$

Let $I\left(Z_{1}, Z_{2}\right.$, e) denote a kernel that equals 1 when two conformable vectors $Z_{1}$ and $\mathrm{Z}_{2}$ are within the maximum-norm distance e of each other and 0 otherwise. Correlation-integral estimators of the joint probabilities in equation $\{7\}$ can then be written as:

$$
\begin{gathered}
C_{1}(m+k, n, e, p) \equiv \frac{2}{p(p-1)} \sum_{t} \sum_{s} I\left(S P_{t}^{m+k}-S P_{s}^{m+k}, e\right) . I\left(T V_{t}^{n}-T V_{s}^{n}, e\right) \\
C_{2}(k, n, e, p) \equiv \frac{2}{p(p-1)} \sum_{t} \sum_{s} I\left(S P_{t}^{k}-S P_{s}^{k}, e\right) . I\left(T V_{t}^{n}-T V_{s}^{n}, e\right) \\
C_{3}(m+k, e, p) \equiv \frac{2}{p(p-1)} \sum_{t} \sum_{s} I\left(S P_{t}^{m+k}-S P_{s}^{m+k}, e\right) \\
C_{4}(k, e, p) \equiv \frac{2}{p(p-1)} \sum_{t} \sum_{s} I\left(S P_{t}^{k}-S P_{s}^{k}, e\right)
\end{gathered}
$$

$t, s=\max (k, n)+1, \ldots, T-m+1$, and $p=T+1-m-\max (k, n)$. Using the joint probability estimators in equation $\{8\}$, the test statistic defined as:

$$
\sqrt{p}\left(\frac{C_{1}(m+k, n, e, p)}{C_{2}(k, n, e, p)}-\frac{C_{3}(m+k, e, p)}{C_{4}(k, e, p)}\right) \approx N\left(0, \sigma^{2}(m, k, n, e)\right)
$$


here a consistent estimated of the variance is estimated as proposed by Hiemstra and Jones (1994) $)^{5}$. They said that, given values of $m, k$, and $n \geq 11$ and $e>0$, if $S P_{t}$ does not nonlinearity Granger-cause $T V_{t}$ then the test statistic in equation $\{9\}$ distributes asymptotically as a normal distribution with zero mean and a constant variance ${ }^{6}$. Since the test statistics are asymptotically normal, the conventional critical values apply when they are adopted to test the null hypothesis that stock price $\left(S P_{t}\right)$ fails to nonlinearly Granger-cause trading volume $\left(T V_{t}\right)$. For test the hypothesis that trading volume does not nonlinearly Granger-cause stock price, similar procedure is followed.

\subsection{DATA AND SAMPLE PERIOD}

The daily stock returns are computed from daily closing prices for the KSE-100 Index. The trading volume series is total trading volume on the Karachi Stock Exchange (KSE). The study covers the period from January 1, 2001 to March 31, 2006 with a total number of observations 1266. To assess the robustness of the empirical findings, the whole sample period is split into two non-overlapping subperiods with different frequency. The first sub-period ranging from $1^{\text {st }}$ January 2001 to $31^{\text {st }}$ December 2003 (730 observations) and the second sub-period spans from $1^{\text {st }}$ January 2004 to $31^{\text {st }}$ March 2006 (536 observations).

The daily stock returns are continuous rates of return, computed as 100 times the first difference of the natural logarithm of the daily stock price, $S P_{t}$, in successive time periods; that is, $100 * \ln \left(S P_{t} / S P_{t-1}\right)^{7}$. The percentage in trading volume, $T V_{t}$, is expressed analogously; that is, $100 * \ln \left(T V_{t} / T V_{t-1}\right)$. The daily KSE-100 Index and Karachi Stock Exchange trading volume are obtained from First National Equities Limited databases.

${ }^{5}$ As said by Hiemstra and Jones (1994), a significantly positive test statistics in equation (9) suggests that lagged values of trading volume series help in forecasting the stock price movements, whereas a significant negative value suggests that knowledge of the lagged values of trading volume series confounds the prediction of stock prices. For this reason, the tests statistic in equation (9) is evaluated with righttailed critical values when testing for the presence of Granger causality.

${ }^{6}$ Hiemstra and Jones (1993) said based on Monte Carlo experiments relating to the finite-sample size of the test that the test is robust to the presence of structural breaks in time series and contemporaneous correlation in VAR errors.

${ }^{7}$ The stock return is only capital gain is not a total market return since dividends are not included. 
Because causality tests are sensitive to non-stationarity, it is important to check the time series properties of the said series. The study thus uses the augmented DickeyFuller test to test whether the series are stationary at their levels or at first differences. The augmented Dickey-Fuller regressions are estimated with a constant. Using t-test, it is found that the linear time trend is not statistical significant in both regressions, therefore, regressions are estimated without linear trend. To determine the number of augmentation terms, the study uses a general-to-specify datadependent procedure in Hall (1993). In this procedure, initially the maximum lag order based on the nature of data is used to estimate the regression and then a $t-$ or $F$-test is used to eliminate insignificant augmentation terms.

Table 1

Descriptive Statistics and ADF-statistics for Daily Stock Index (KSE-100) Return and Trading Volume

\begin{tabular}{|c|c|c|c|}
\hline $\begin{array}{l}\text { Time Period } \\
\text { (No. of } \\
\text { Observation) }\end{array}$ & Statistics & $\begin{array}{l}\text { Return on Daily } \\
\text { KSE-100 Stock } \\
\text { Index }\end{array}$ & $\begin{array}{c}\% \text { Change in } \\
\text { Total Daily } \\
\text { Trading Volume }\end{array}$ \\
\hline $\begin{array}{c}\text { January } 1,2001 \\
\text { to } \\
\text { March 31, } 2006 \\
\text { (1266) }\end{array}$ & $\begin{array}{l}\text { Mean } \\
\text { Std. Dev. } \\
\text { Skewness } \\
\text { Kurtosis } \\
\text { ADF-statistic }\end{array}$ & $\begin{array}{c}0.125 \\
1.765 \\
0.012 \\
8.849 \\
-10.047^{*}\end{array}$ & $\begin{array}{c}1.478 \\
31.664 \\
0.406 \\
6.673 \\
-26.179 * \\
\end{array}$ \\
\hline $\begin{array}{c}\text { January } 1,2001 \\
\text { to } \\
\text { December } 31,2003 \\
(730)\end{array}$ & $\begin{array}{l}\text { Mean } \\
\text { Std. Dev. } \\
\text { Skewness } \\
\text { Kurtosis } \\
\text { ADF-statistic }\end{array}$ & $\begin{array}{c}0.121 \\
1.744 \\
-0.035 \\
8.493 \\
-9.219^{*} \\
\end{array}$ & $\begin{array}{c}1.125 \\
32.761 \\
0.312 \\
5.876 \\
-19.326 * \\
\end{array}$ \\
\hline $\begin{array}{c}\text { January 1, } 2004 \\
\text { to } \\
\text { March 31, } 2006 \\
\text { (536) }\end{array}$ & $\begin{array}{l}\text { Mean } \\
\text { Std. Dev. } \\
\text { Skewness } \\
\text { Kurtosis } \\
\text { ADF-statistic }\end{array}$ & $\begin{array}{c}0.131 \\
1.796 \\
0.069 \\
9.262 \\
-7.587^{*}\end{array}$ & $\begin{array}{c}1.93 \\
31.109 \\
0.578 \\
8.064 \\
-10.929 *\end{array}$ \\
\hline
\end{tabular}

The augmented Dickey-Fuller test is calculated with intercept. The critical values of ADF test are -3.96 and -3.41 at 0.01 and 0.05 , respectively. ${ }^{*}$ indicates significant difference of test statistic from critical value at 0.01 level of significance.

The computed Dickey-Fuller $t$ - statistics and descriptive statistics are reported in Table 1 for the entire sample period from 1 January 2001 to 31 March 2006 and for the two sub-periods. It can be seen from the table that stock returns in KSE-100 
Index (except the full-length period) and stock market trading volume change have positive skewness, and significant excess kurtosis is observed for stock returns. Based on the estimated ADF test statistics, the unit root null hypotheses are rejected at the 99 percent confidence level in all cases. It thus can be confirmed that the stock returns and the percentage change in trading volume are stationary at their levels.

A two-step procedure similar to one used in Gallant, Rossi, and Tauchen (1992) is used to remove systematic day-of-the-week and month-of-the-year calendar effects from stock returns and percentage volume changes. Both the mean and variance of the stock returns and trading volume series are adjusted for both of these effects. For the volume series the two-step adjustment procedure involves estimating the following regression equations:

Mean Equation: $\quad P V_{t}=D_{t} \Psi_{P V}+\varsigma_{t}$

Variance Equation: $\quad \ln \left(\hat{\zeta}_{t}^{2}\right)=D_{t} \Phi_{P V}+v_{t}$

where $D_{t}$ denotes a vector of weekly and monthly dummy variables, $\Psi_{P V}$, and $\Phi_{P V}$ denote parameter vectors, $\zeta_{t}$, and $v_{t}$ denote error terms, and $\hat{\zeta}_{t}$ denotes the ordinary least squares (OLS) estimated residual in equation $\{10\}$. Analogous regressions are estimated for stock returns.

For each series, the variance equation $\{11\}$ is used to standardize the residuals from mean equation $\{10\}$. For instance, the calendar-adjusted, standardized percentage volume changes are computed as:

$$
T V_{t}^{*}=\frac{\hat{\zeta}_{t}}{\exp \left(D_{t} \hat{\Phi}_{P V} / 2\right)}
$$

where $\hat{\Phi}_{P V}$ denotes the OLS estimate of $\Phi_{P V}$. The stock returns are adjusted analogously. The study used the calendar-adjusted, standardized stock returns, $\left\{S R_{t}^{*}\right\}$, and percentage volume changes, $\left\{T V_{t}^{*}\right\}$, to explore the causal linkages.

\section{EMPIRICAL FINDINGS}

\subsection{CROSS-CORRELATION ANALYSIS}

As a first step to investigate the interactions between stock returns and percentage volume changes, simply cross-correlation coefficients, $C C_{S P^{*}, V R^{*}}$, are calculated as follows: 


$$
C C_{S P^{*}, V R^{*}}=\operatorname{Cov}\left(S P_{t}^{*}, V R_{t}^{*}\right) /\left(S \cdot D\left(S P_{t}^{*}\right)\left(S . D\left(V R_{t}^{*}\right)\right)\right.
$$

where $S R_{t}^{*}$ and $T V_{t}^{*}$ are defined as above. Cov denotes covariance and S.D abbreviates standard deviation. The estimated cross-correlation coefficients for the entire sample period as well as for the two sub-sample periods are reported in Table 2 .

Table 2

Cross-Correlation Coefficients between Stock Returns and Percentage Trading Volume Changes

\begin{tabular}{|c|c|c|c|c|c|c|}
\hline \multirow[t]{2}{*}{ \# } & \multicolumn{2}{|c|}{$\begin{array}{c}1 \text { January } 2001 \\
\text { to } \\
\text { 31 March } 2006\end{array}$} & \multicolumn{2}{|c|}{$\begin{array}{c}1 \text { January } 2001 \\
\text { to } \\
31 \text { December } 2003\end{array}$} & \multicolumn{2}{|c|}{$\begin{array}{c}\text { 1 January } 2004 \\
\text { to } \\
\text { 31 March } 2006\end{array}$} \\
\hline & Lag & Lead & Lag & Lead & Lag & Lead \\
\hline 0 & $0.201 *$ & $0.201 *$ & $0.147^{*}$ & $0.147^{*}$ & $0.280 *$ & $0.280^{*}$ \\
\hline 1 & 0.000 & 0.006 & $-0.047 *$ & 0.016 & $0.067 *$ & -0.009 \\
\hline 2 & 0.005 & $-0.164^{*}$ & 0.001 & $-0.138^{*}$ & 0.010 & $-0.203^{*}$ \\
\hline 3 & -0.016 & 0.014 & -0.009 & $0.051^{*}$ & -0.026 & -0.041 \\
\hline 4 & 0.009 & 0.018 & 0.031 & -0.005 & -0.022 & $0.052 *$ \\
\hline 5 & 0.044 & $-0.073^{*}$ & 0.012 & $-0.049 *$ & $0.092 *$ & $-0.109^{*}$ \\
\hline 6 & -0.004 & $-0.052 *$ & -0.034 & $-0.046^{*}$ & 0.040 & $-0.060^{*}$ \\
\hline 7 & 0.011 & $0.054 *$ & 0.022 & 0.046 & -0.005 & $0.065^{*}$ \\
\hline
\end{tabular}

*indicates significant at $5 \%$ level of significance.

Significant positive correlations observed between stock returns and percentage volume changes at level and on average in lead-lengths for all the examined periods. These findings are providing some evidence of the associations between stock returns and trading volume: a theme that is explored by applying linear and nonlinear Granger causality tests.

\subsection{LINEAR GRANGER CAUSALITY TEST RESULTS}

As mentioned earlier, the results of the $\mathrm{ADF}$ test provided evidence that returns in KSE-100 Index and percentage volume changes on the Karachi Stock Exchange are stationary at their level for the entire sample period and for the two sub-periods either. Thus, to look at the nonlinear Granger causality, the study estimated the VAR models specified in equations $\{3\}$ and $\{4\}$ with calendar-adjusted stock returns and percentage volume change. The models can be expressed as follows:

$$
\begin{aligned}
& S P_{t}^{*}=a_{0}+a_{1} S P_{t-1}^{*}+\cdots+a_{k} S P_{t-k}^{*}+b_{1} T V_{t-1}^{*}+\cdots+b_{n} T V_{t-n}^{*}+u_{t}^{*} \\
& T V_{t}^{*}=a_{0}^{\prime}+a_{1}^{\prime} T V_{t-1}^{*}+\cdots+a_{n}^{\prime} T V_{t-n}^{*}+b_{1}^{\prime} S P_{t-1}^{*}+\cdots+b_{k}^{\prime} S P_{t-k}^{*}+v_{t}^{*}
\end{aligned}
$$


The Akaike's (1974) information criterion (AIC) is used to determine the appropriate lag lengths for VAR models. Table 3 reports the results of the Granger causality test. Lag lengths on the dependent and independent variables, and computed $F$-values with their $p$-values are also reported.

Table 3

Linear Granger Causality Test Results

\begin{tabular}{|c|c|c|c|c|c|}
\hline $\begin{array}{l}\text { Time } \\
\text { Period }\end{array}$ & Lag & $\begin{array}{c}\text { H: Volume } \\
\text { Changes Do Not } \\
\text { Linear Cause } \\
\text { Stock Returns }\end{array}$ & $p$-value & $\begin{array}{c}\text { H: Stock } \\
\text { Returns Do Not } \\
\text { Linear Cause } \\
\text { Volume Change }\end{array}$ & $p$-value \\
\hline $\begin{array}{c}01 / 01 / 01 \\
\text { to } \\
31 / 03 / 06 \\
(1266) \\
\end{array}$ & $\begin{array}{c}5 \\
7 \\
10 \\
15 \\
\end{array}$ & $\begin{array}{l}0.451 \\
0.579 \\
0.537 \\
0.459 \\
\end{array}$ & $\begin{array}{l}0.813 \\
0.773 \\
0.864 \\
0.960 \\
\end{array}$ & $\begin{array}{l}7.647 \\
6.817 \\
5.223 \\
3.830 \\
\end{array}$ & $\begin{array}{l}0.000 \\
0.000 \\
0.000 \\
0.000 \\
\end{array}$ \\
\hline $\begin{array}{c}01 / 01 / 01 \\
\text { to } \\
31 / 12 / 03 \\
(730) \\
\end{array}$ & $\begin{array}{c}2 \\
5 \\
10 \\
15\end{array}$ & $\begin{array}{l}1.157 \\
0.605 \\
0.562 \\
0.377 \\
\end{array}$ & $\begin{array}{l}0.314 \\
0.696 \\
0.845 \\
0.985 \\
\end{array}$ & $\begin{array}{l}6.346 \\
3.336 \\
3.305 \\
2.611 \\
\end{array}$ & $\begin{array}{l}0.002 \\
0.005 \\
0.000 \\
0.000 \\
\end{array}$ \\
\hline $\begin{array}{c}01 / 01 / 04 \\
\text { to } \\
31 / 03 / 06 \\
(536) \\
\end{array}$ & $\begin{array}{c}5 \\
7 \\
10 \\
15\end{array}$ & $\begin{array}{l}1.690 \\
1.873 \\
1.091 \\
0.796 \\
\end{array}$ & $\begin{array}{l}0.135 \\
0.072 \\
0.366 \\
0.683 \\
\end{array}$ & $\begin{array}{l}5.135 \\
4.745 \\
3.523 \\
3.000 \\
\end{array}$ & $\begin{array}{l}0.000 \\
0.000 \\
0.000 \\
0.000 \\
\end{array}$ \\
\hline
\end{tabular}

Bold lag lengths are optimal that set with the Akaike (1974) information criterion. The results of Granger causality are very sensitive to lag order. The study therefore used some other lag intervals besides the optimal lag lengths to check the robustness of the results. Focusing on the rejections of the null hypothesis of Granger noncausality at the five percent nominal significance level, the Granger test is able to reject the null hypothesis that stock returns do not cause volume changes for the entire sample period from 1 January 2001 to 31 Mach 2006 and for both the nonoverlapping sub-periods alike. It means that there is unidirectional Granger causality from stock returns to percentage volume changes. This piece of evidence is robust to other examined lag lengths.

On the other hand, the null hypothesis of Granger noncausality from volume changes to stock returns cannot be rejected at 5 percent significance in the full-length period and in either sub-period. The null can be rejected, however, at 8 percent significance level in only optimal lag length selected by AIC for the second sub-period from 1 January 2003 to 31 Mach 2006. Overall, the null hypothesis of Granger noncausality 
from stock returns to percentage volume changes is rejected and from percentage volume changes to stock returns is accepted. Thus, it can be concluded that there is a unidirectional linear Granger causality from stock returns to percentage volume changes.

\subsection{NONLINEAR GRANGER CAUSALITY TEST RESULTS}

Using the traditional linear Granger causality tests, it is found that there is unidirectional linear causality from stock returns to change in trading volume. As reported earlier, the traditional Granger causality test is not able to explore the nonlinear relations; the study therefore uses the modified version of Baek and Brock's (1992a) nonlinear Granger causality test to expose the nonlinear interactions between stock returns and percentage volume changes. The study follows Hiemstra and Jones (1994) in order to select values for the lead length $m$, the lag length $k$ and $n$, and the scale parameter $e$. Hence, for all cases, the lead length of $m=1$, common lag lengths of 1 to 8 lags and a common scale parameter of $e=1.5 \sigma$ are used to apply the test on standardized series ${ }^{8}$.

The modified version of Baek and Brock's nonlinear Granger causality test applied to estimated residuals from the VAR models identified for linear Granger causality test. The estimated results are reported in Table 4 . From the table, it can be seen some fascinating evidence. There is evidence of unidirectional nonlinear Granger causality between stock returns and the percentage trading volume changes that runs from volume to stock returns for both the examined sub-periods. However, the analysis is not able to find any reverse causation for these two variables.

Table 4

Nonlinear Granger Causality Test Results

\begin{tabular}{|c|c|c|}
\hline$k=n$ & $\begin{array}{l}\text { H: Volume Changes Do Not } \\
\text { Nonlinear Cause Stock } \\
\text { Returns }\end{array}$ & $\begin{array}{c}\text { H: Stock Returns Do Not } \\
\text { Nonlinear Cause Volume Change }\end{array}$ \\
\hline \multicolumn{3}{|c|}{ Entire Sample Period: January 2001 to March 2006} \\
\hline 1 & $6.404^{*}$ & -2.149 \\
\hline 2 & 1.029 & -2.857 \\
\hline 3 & 1.029 & -1.987 \\
\hline 4 & $3.221 *$ & -1.074 \\
\hline 5 & 0.135 & -5.365 \\
\hline 6 & 1.028 & -3.218 \\
\hline 7 & 0.983 & -3.217 \\
\hline 8 & 0.938 & -3.215 \\
\hline
\end{tabular}

${ }^{8}$ where $\sigma=1$ denotes the standard deviation of the standardized time series. 


\begin{tabular}{ccc}
\hline & First Sub-Sample Period: January 2001 to December 2003 \\
\hline 1 & $1.865^{* *}$ & -1.925 \\
2 & $5.713^{*}$ & -2.991 \\
3 & $5.769^{*}$ & -3.456 \\
4 & $5.765^{*}$ & -5.765 \\
5 & $3.780^{*}$ & -1.921 \\
6 & $1.858^{* *}$ & -2.635 \\
7 & $1.857^{* *}$ & -3.125 \\
8 & $1.855^{* *}$ & -3.150 \\
\hline & Second Sub-Sample Period: January 2004 to March 2006 \\
\hline 1 & 1.256 & -3.850 \\
2 & 1.351 & 1.604 \\
3 & 1.416 & 1.603 \\
4 & $4.991 *$ & -3.844 \\
5 & $3.414^{*}$ & -1.281 \\
6 & $2.759^{*}$ & -2.559 \\
7 & $2.757^{*}$ & -2.555 \\
8 & $2.688^{*}$ & -2.873 \\
\hline
\end{tabular}

${ }^{*}$ significant at the 1 percent level of significance for a one-sided test.

** significant at the 10 percent level of significance for a one-sided test.

This piece of evidence is robust for about all the common lag lengths used in conducting the test. For the entire sample period, there is no significant evidence of nonlinear Granger causality between stock returns and trading volume in either direction, except lag length 1 and 4. At these lag lengths; the modified Baek and Brock's test rejects the null hypothesis of nonlinear Granger noncausality from trading volume to stock returns.

It is interesting to compare the results of the modified Baek and Brock's (1992a) test for nonlinear Granger causality with linear Granger causality test results. Note in Table 3 that the test statistics only provide strong evidence of significant linear unidirectional causality from stock returns to percentage volume changes. Quite the opposite, Table 4 reveals evidence of nonlinear Granger causality from percentage volume changes to stock returns.

\section{CONCLUSIONS}

This document examines the dynamic interactions between stock prices and aggregate trading volume using linear and nonlinear Granger causality tests. The study applies the tests to daily KSE-100 Index stock returns and percentage volume changes in Karachi Stock Exchange trading volume over the period from January 2001 to March 2006. In addition, this period is divided into two non-overlapping sub-periods: January 2001 to December 2003 and January 2004 to March 2006. In 
each case, a two-step procedure similar to one used in Gallant et al. (1992) is used to remove systematic day-of-the-week and month-of-the-year calendar effects from stock returns and percentage volume changes.

Linear Granger causality test provides very strong evidence of significant unidirectional linear Granger causality from stock returns to percentage volume changes in the entire sample period and in both the sub-periods as well. The Granger causality tests results are very sensitive to lag lengths, the study therefore used Akaike (1974) information criterion to select the optimal lag lengths. Along with this, some others lag lengths are also used in conducting the test to examine the robustness of the results. It is found that these results are strongly consistent for all the common examined lag lengths.

Regarding nonlinear Granger causality between stock returns and the percentage change in trading volume, the analysis provides a quite different story. It provides evidence of significant unidirectional nonlinear Granger causality from percentage volume changes to stock returns in both the sub-periods for all the examined lag lengths. For entire sample period, the analysis, however, rejects the same hypothesis for 2 out of 8 lag lengths. This piece of evidence is opposite to the linear Granger causality test, which reports unidirectional causality from stock returns to trading volume.

In sum, it can be stated in the light of both linear and nonlinear Granger causality tests that volume has significant nonlinear explanatory power for stock returns, whereas stock returns have linear explanatory power for trading volume. It means that forecasts of one of these variables can be improved by knowledge of the other. The findings therefore are of particular interest to investors in Pakistan. These findings contribute to the empirical literature by signifying the presence of linear unidirectional Granger causality from stock returns to volume and nonlinear Granger causality from volume to stock returns. The analysis may establish useful base for future empirical work in this field and suggests that researchers should consider nonlinearity in modeling for the joint dynamics of stock prices and trading volume.

\section{REFERENCES}

Alexander, S. (1961). 'Price Movements in Speculative Markets: Trends or Random Walks', Industrial Management Review, No. 2, pp. 7-26.

Alexander, S. (1964). 'Price Movements in Speculative Markets: Trends or Random Walks', No. 2, in P. Cootner (ed), The Random Character of Stock Market Prices, MIT Press Cambridge, MA.

Baek, E. and W. Brock. (1992a). 'A General test for Nonlinear Granger Causality: Bivariate Model', Working Paper, Lowa State University and University of Wisconsin, Madison. 
Baek, E. and W. Brock. (1992b). 'A Nonparametric for Independence of a Multivariate Time Series', Statistica Sinica, Vol. 2, pp. 137-156.

Blume, L., D. Easley and M. O'Hara (1994). 'Market Statistics and Technical Analysis: The Role of Volume', Journal of Finance, Vol. 49, No. 1, pp. 153-181.

Brock, W., D. Hsieh and B. LeBaron (1991). 'A Test of Nonlinear Dynamics, Chaos, and Instability: Statistical Theory and Economic Evidence', MIT Press, Cambridge, Mass.

Brock, W., (1993). "Beyond Randomness: Emergent Noise" Working Paper, University of Wisconsin, Madison.

Campbell, J., S. Grossman and J. Wang (1993). 'Trading Volume and Serial Correlation in Stock Returns', Quarterly Journal of Economics, Vol. 108, pp. 95-939.

Chen, G., M. Firth and O. M. Rui (2001). 'The Dynamic Relation between Stock Returns, Trading Volume and Volatility', The Financial Review, Vol. 38, pp. 153174.

Chordia, T. and B. Swaminathan (2000). 'Trading Volume and CrossAutocorrelation in Stock Returns', Journal of Finance, Vol. 55, pp. 913-935.

Copeland, T. (1976). 'A model of asset Trading under the Assumption of Sequential Information Arrival', Journal of Finance, Vol. 31, pp. 135-155.

Clark, P. (1973). 'A Subordinated Stochastic Process Model with Finite Variance for Speculative Prices', Econometrica, Vol. 41, pp. 135-155.

Delong, J., A. Shleifer, L. Summers and B. Waldmann (1990). 'Positive Feedback Investment Strategies and Destabilizing Speculation', Journal of Finance, Vol. 45, pp. 379-395.

Epps, T. and M. Epps (1976). 'The Stochastic Dependence of Securities Prices Changes and Transaction Volumes: Implications for the Mixture of Distributions Hypothesis', Econometrica, Vol. 44, pp. 305-321.

Fama, E. (1963). 'Mandelbrot and the Stable Paretian Hypothesis', Journal of Business, Vol. 35, pp. 420-429.

Fama, E. F. (1970). 'Efficient Capital Market: Review of Theory and Empirical Work', Journal of Finance, Vol. 25, pp. 383-417.

Fama, E. (1965). 'The Behavior of Stock Market Prices', Journal of Business, Vol. 38 , pp 34-105.

Fan, X., Groenwold, N., and Wu, Y. (2003). 'The Stock Return-Volume Relation and Policy Effects: The Case of the Energy Sector', Proceedings of the $15^{\text {th }}$ Annual Conference of the Association for Chinese Economics Studies Australia (ACESA).

Gallant, R., P. Rossi and G. Tauchen (1992). 'Stock Prices and Volume', Review of Financial Studies, Vol. 5, pp. 199-242. 
Ghysels, E., C. Gourierous and J. Jasiak (2000). 'Causality between Returns and Trading Volumes', Annales, D’Economie Et De Statistique, No. 60, pp. 191-206.

Granger, C. (1969). 'Investigation Causal Relation by Econometric Models and Cross-Spectral Methods', Econometrica, Vol. 37, pp. 424-438.

Granger, C., and P. Newbold (1986). 'Forecasting Economic Time Series', $2^{\text {nd }}$ ed., Academic Press, Orlando, Fla.

Granger, M., and O. Morgenstern (1963). 'Spectral Analysis of New York Stock Market Prices', Kyklos, Vol. 16, pp. 1-27.

Hall, A., (1993). "Testing for a Unit Root in Time Series with Pretest Data Based Model Selection" Working Paper, North Carolina State University.

Hiemstra, C. and Jones, J. D. (1994). 'Testing for Linear and Nonlinear Granger Causality in the Stock Price-Volume Relation', Journal of Finance, Vol. XLIX, No. 5, pp. 1639-1664.

Hiemstra, C., (1993). 'Monte Carlo Results for Modified Version of the Baek and Brock Nonlinear Granger Causality Test', Working Paper, University of Strathclyde and Securities and Exchange Commission.

Hinieh, M. and D. Patterson (1985). 'Evidence of Nonlinearity in Stock Returns, Journal of Business and Economic Statistics, Vol. 3, pp. 69-77.

Husain, F. (1997). 'The Random Walk Model in the Pakistani Equity Market: An Examination,, The Pakistan Development Review, Vol. 36, No. 3, pp. 221-240.

Jain, P. and G. Joh (1988). 'The Dependence between Hourly Prices and Trading Volume, Journal of Financial and Quantitative Analysis, Vol. 23, pp. 269-283.

Jennings, R., L. Starks and J. Fellingham (1981). 'An Equilibrium Model of Asset Trading with Sequential Information Arrival', Journal of Finance, Vol. 36, pp. 142-161.

Lakonishok, J. and S. Smidt (1989). 'Past Prices Changes and Current Trading Volume', Journal of Portfolio Management, Vol. 15, pp. 18-24.

Larson, A. (1960). 'Measurement of a Random Process in Futures Prices', Food Research Institute, Vol. 1, pp. 313-324.

LeBaron, B. (1992). 'Persistence of the Dow Jones Index on Rising Volume', Working Paper, University of Wisconsin, Madison.

Lo, A. W. \& A. Craig Mackinlay (1988). 'Stock Prices do not Follow Random Walks: Evidence from A Simple Specification Test', Review of Financial Studies, Vol. 1, pp. 41-66.

Mandelbrot, B. (1963). 'The Variation of Certain Speculative Prices, Journal of Business, Vol. 35, pp. 394-419.

Osborne, M. F.M. (1959). 'Brownian Motion in the Stock Market', Operations Research, Vol. 7, No. 2, pp. 145-173. 
Rogalski, R. (1978). 'The Dependence of Price and Volume', Review of Economics and Statistics, Vol. 36, pp. 268-274.

Scheinkman, J. and B. LeBaron (1989). 'Nonlinear Dynamic and Stock Returns, Journal of Business, Vol. 62, pp. 311-337.

Smirlock, M. and L. Starks (1988). 'An Empirical Analysis of the Stock PriceVolume Relationship', Journal of Banking and Finance, Vol. 12, pp. 31-41.

Rashid, A., (2006). "Random Walk Tests for KSE-100 Index: Evidence and Implications, Business Review, Vol. 1, No 1, pp. 77-89.

Rashid, A., (2005). "Stock Prices Behave Non-Randomly: Evidence from Karachi Stock Exchange, Pakistan Business Review, Vol. 7, No. 2, pp. 58-82.

Ying, C. C. (1966). Market Prices and Volumes of Sales', Econometrica, Vol. 34, No. 3, pp. 676-685.

\section{DELINQUENY AND CRIME}

Healy and Bronner compared delinquent youths with their non delinquent siblings, to see what differences there were between them. The most important finding was that over 90 percent of the delinquents compared to 13 percent of their non delinquent siblings had unhappy home lives and felt discontented with their life circumstances. The nature of the unhappiness differed: some felt rejected by parents; others felt inadequate or inferior; others were jealous of siblings; still others were affected by more deep seated mental conflict. Delinquency was seen as solution to these problems. It brought attention to those who suffered from parental neglect, provided support from peers for those who felt inadequate, brought on punishment and therefore reduced guilt feelings.

The general theme is clear: unfortunate, unhappy family circumstances, leading to personal psychological problems of adjustment for the youth, which in turn are in some way solved by the commission of delinquent acts.

William Healy and Augusta F. Bronner New Light on Delinquency and its Treatment, New Haven, Conn: Yale University Press, 1936. 